Research Article

\title{
Green Synthesis of Acid Esters from Furfural via Stobbe Condensation
}

\author{
Shubhra Banerjee, Ravibabu A. Tayade, and Bhagyashree D. Sharma \\ Department of Chemistry, Institute of Science, R. T. Road, Nagpur 440 001, India \\ Correspondence should be addressed to Bhagyashree D. Sharma; bhagyashree_4sep@rediffmail.com
}

Received 15 December 2011; Accepted 4 June 2012

Academic Editor: Pilar Hernandez-Munoz

Copyright (c) 2013 Shubhra Banerjee et al. This is an open access article distributed under the Creative Commons Attribution License, which permits unrestricted use, distribution, and reproduction in any medium, provided the original work is properly cited.

\begin{abstract}
Solvent-free Stobbe condensation of furfural $\mathbf{1}$ with dimethyl succinate $\mathbf{2}$ under anhydrous conditions at room temperature using dry-solid potassium tertiary butoxide gave 3-carbomethoxy, 4-furyl-3-butenoic acid 3, which upon methylation followed by Stobbe condensation reaction with different aldehydes and/or ketones under anhydrous conditions at room temperature afforded substituted carbomethoxy acids $\mathbf{5 a}-\mathbf{f}$. These acid ester products were saponified to the corresponding dicarboxylic acids $\mathbf{6 a}-\mathbf{f}$ which are useful in the synthesis of photochromic fulgides.
\end{abstract}

\section{Introduction}

Fulgides are important for their photochromic properties [1-3]. Stobbe condensation [4-10], a C-C bond forming reaction, is a pathway to fulgides. A lot of research has been done on photochromic fulgides; among them, furan ring containing fulgides [11] have maintained the interest of researchers through decades of development of organic synthesis.

During the last few years, solvent-free reactions [12, 13] for the different organic synthesis have been a field of increasing interest in synthetic organic chemistry because of their ease to occur. The present work depicts a unique one- pot synthesis method in which solvent-free conditions allow improving the yield and expediting the reaction. Here, different substituted carbonyl compounds including aldehydes, aromatic, and alicyclic, aliphatic ketones and an active methylene compound, namely, dimethyl succinate, were condensed in anhydrous condition. The reaction is feasible in a dry agate mortar at room temperature, avoiding hazards of using any solvent.

\section{Experimental}

All chemicals were of reagent grade quality and used without further purification. Melting points were measured on a melting point apparatus and are uncorrected. NMR spectra were recorded on a Bruker $300 \mathrm{MHz}$ spectrometer. Chemical shifts are reported in ppm relative to tetramethyl silane as an internal standard. The infrared spectra were obtained on a Bruker IFS $66 \mathrm{~V}$ Fourier transform spectrometer using $\mathrm{KBr}$ pellets. The compounds were scanned for UV-visible spectra [14] using Perkin Elmer spectrophotometer.

Procedure for Preparation of 3-Carbomethoxy,4-furyl,3butenoic Acid (3). A homogenous mixture of furfural $1(0.96 \mathrm{~g}, 0.01 \mathrm{~mole})$ and dimethyl succinate $2(1.46 \mathrm{~g}$, 0.01 mole) was added to potassium tert. butoxide ( $1.13 \mathrm{~g}$, 0.01 mole) and well ground with a pestle for $10 \mathrm{~min}$. It was exposed to air for another $15 \mathrm{~min}$. Upon neutralization with dil. $\mathrm{HCl}$ at $0^{\circ} \mathrm{C}$ and usual work up [15], crude product, namely, 3-carbomethoxy,4-furyl, 3-butenoic acid 3 was obtained, which was recrystallized from benzene-pet. Ether (see Scheme 1)

Yield 83\%, ${ }^{1} \mathrm{H}$ NMR $\left(300 \mathrm{MHz}, \mathrm{CDCl}_{3}\right)(\delta / \mathrm{ppm}): 1.25$ (s, $2 \mathrm{H}), 3.04(\mathrm{~s}, 3 \mathrm{H}), 7.5(\mathrm{~s}, 1 \mathrm{H}), 7.5701-7.580$ (AMX, 3H). FTIR $\left(\mathrm{KBr}, \mathrm{cm}^{-1}\right) 1170(\mathrm{C}-\mathrm{O}), 1475.26\left(\right.$ aliphatic $\left.\mathrm{CH}_{2}\right) 1654(\mathrm{C}=\mathrm{O}$ acid), $1700(\mathrm{C}=\mathrm{O}$ ester $), 2511\left(-\mathrm{OCH}_{3}\right)$. UV $\lambda_{\max }(\mathrm{EtOH})$ $211.95 \mathrm{~nm}(\log \varepsilon 3.131)$. eq.wt. (found) 205.95 required for $\mathrm{C}_{10} \mathrm{H}_{10} \mathrm{O}_{5}$ eq. wt. 210.18 .

Procedure for Preparation of Methyl 3-Carbomethoxy,4furyl,3-butenoate (4). 3-Carbomethoxy,4-furyl, 3-butenoic acid $3(1 \mathrm{~g})$ in ethereal solution was esterified by 


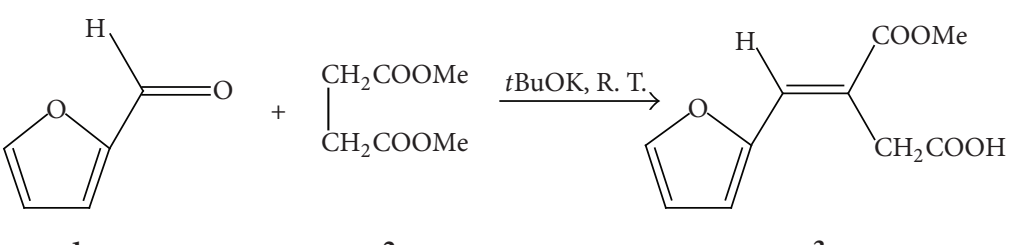

1

2

SCHEme 1: One-pot synthesis of acid ester 3.

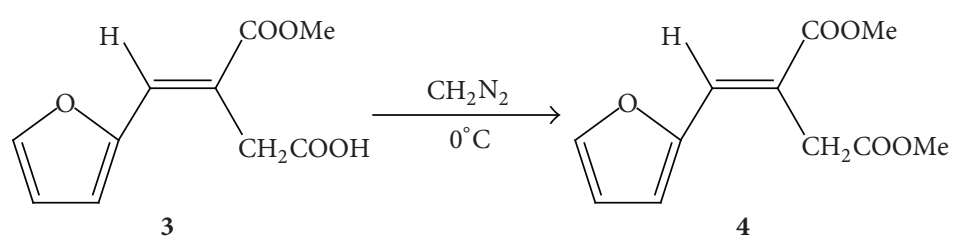

SCHEME 2: Methylation.

diazomethane [16] being generated from nitrosomethylurea $(0.6 \mathrm{~g})$ added to a reaction mixture of $50 \% \mathrm{KOH}$ solution $(4.0 \mathrm{~mL})$ and ether $(10.0 \mathrm{~mL})$. After $15 \mathrm{~min}$, the reaction mixture was washed with $10 \% \mathrm{Na}_{2} \mathrm{CO}_{3}$ solution three times. The organic layer was dried over anhydrous sodium sulphate. Removal of solvent gave the crude semisolid diester, namely, methyl 3-carbomethoxy,4-furyl,3-butenoate, 4 (1.2 g, 90\% yield) (see Scheme 2).

1,1-Cyclopentylidene-1' -carbomethoxy,3(2-furyl)-prop-2-ene2-oic Acid (5a). To a neat mixture of the diester 4 (2.24 g, 0.01 mole $)$ and cyclopentanone $(0.84 \mathrm{~g}, 0.01 \mathrm{~mole})$, was added dried potassium tertiary butoxide ( $1.13 \mathrm{~g}, 0.01 \mathrm{~mole})$. The reaction mixture was well mixed and ground for $10 \mathrm{~min}$. It was further exposed to air. Acidification followed by usual workup [15] gave the acid ester 5a recrystallised from benzene-pet. ether as reddish brown crystals.

Yield $78 \%,{ }^{1} \mathrm{H}$ NMR $(300 \mathrm{MHz}, \mathrm{DMSO})(\delta / \mathrm{ppm})$ : 2.58-2.59 (m, 8H, alicyclic $\left.\mathrm{CH}_{2}\right), 3.02$ (s, 3H, methoxy protons), 7.5523-7.5552 (AMX, 3H, furyl), 7.6 (s, 1H, vinyl). FTIR (KBr, cm ${ }^{-1}$ ) 1174 (C-O), 1480 (alicyclic $\mathrm{CH}_{2}$ ) 1715 ( $\mathrm{C}=\mathrm{O}$ acid), $1735\left(\mathrm{C}=\mathrm{O}\right.$ ester), $2511\left(-\mathrm{OCH}_{3}\right)$. UV $\lambda_{\max }$ (EtOH) $350 \mathrm{~nm}$ (log $\varepsilon 4.1$ ). eq. wt. (found) 273.44 required for $\mathrm{C}_{15} \mathrm{H}_{16} \mathrm{O}_{5}$ eq. wt. 276.29.

1,1-Cyclohexylidene-1' -carbomethoxy,3(2-furyl)-prop-2-ene2-oic Acid (5b). ${ }^{1} \mathrm{H}$ NMR (300 MHz, DMSO) ( $\left.\delta / \mathrm{ppm}\right): 1.66$ (s, 6H, alicyclic $\left.\mathrm{CH}_{2}\right), 2.1\left(\mathrm{~s}, 2 \mathrm{H}\right.$, alicyclic $\left.\mathrm{CH}_{2}\right), 2.94(\mathrm{~s}, 2 \mathrm{H}$, alicyclic $\mathrm{CH}_{2}$ ), 3.02 (s, 3H, methoxy protons), 6.392-6.457, 6.675-6.723, 7.662-7.674 (AMX, 3H, furyl), 7.7 (s, 1H, vinyl). FTIR (KBr, cm $\left.{ }^{-1}\right) 1260(\mathrm{C}-\mathrm{O}), 1480$ (alicyclic $\left.\mathrm{CH}_{2}\right)$ $1614(\mathrm{C}=\mathrm{C}), 1684$ ( $\mathrm{C}=\mathrm{O}$ acid), 1712 ( $\mathrm{C}=\mathrm{O}$ ester). UV $\lambda_{\max }$ (EtOH) $294 \mathrm{~nm}$ (log ع3.32). eq. wt. (found) 292.20 required for $\mathrm{C}_{16} \mathrm{H}_{18} \mathrm{O}_{5}$ eq. wt. 290.30 .

1,1-Isopropylidene-1' -carbomethoxy,3(2-furyl)-prop-2-ene-2oic Acid (5c). ${ }^{1} \mathrm{H}$ NMR (300 MHz, DMSO) ( $\left.\delta / \mathrm{ppm}\right): 1.75$ (s, 3H, aliphatic $\left.\mathrm{CH}_{2}\right), 2.2\left(\mathrm{~s}, 3 \mathrm{H}\right.$, aliphatic $\left.\mathrm{CH}_{2}\right), 3.7(\mathrm{~s}$, $3 \mathrm{H}$, methoxy protons), 6.429-6.442, 6.59-6.60, 7.468-7.491 (AMX, 3H, furyl), 7.6 (s, 1H, vinyl). FTIR $\left(\mathrm{KBr}, \mathrm{cm}^{-1}\right) 1258$ (C-O), $1664(\mathrm{C}=\mathrm{C}), 1685$ ( $\mathrm{C}=\mathrm{O}$ acid), 1715 ( $\mathrm{C}=\mathrm{O}$ ester).
UV $\lambda_{\max }$ (EtOH) $290 \mathrm{~nm}$ (log $\varepsilon 3.2$ ). eq. wt. (found) 252.30; required for $\mathrm{C}_{13} \mathrm{H}_{14} \mathrm{O}_{5}$ eq. wt. 250.42 .

1-Furyl-3-carbomethoxy-4-phenyl Buta-1,3-diene-2-oic Acid (5d). ${ }^{1} \mathrm{H}$ NMR (300 MHz, DMSO) $(\delta / \mathrm{ppm}): 3.7(\mathrm{~s}, 3 \mathrm{H}$, methoxy protons), 6.376-6.389, 6.28-6.63, 7.35-7.46 (AMX, $3 \mathrm{H}$, furyl), 7.5 (s, 5H, phenyl), 7.7 (s, 1H, vinyl), $7.8(\mathrm{~s}, 1 \mathrm{H}$, vinyl). FTIR ( $\left.\mathrm{KBr}, \mathrm{cm}^{-1}\right) 1174(\mathrm{C}-\mathrm{O}), 1480$ (alicyclic $\mathrm{CH}_{2}$ ) $1715(\mathrm{C}=\mathrm{O}$ acid $), 1735$ (C=O ester), $2511\left(-\mathrm{OCH}_{3}\right)$. UV $\lambda_{\max }$ (EtOH) $350 \mathrm{~nm}$ (log $\varepsilon 4.1$ ). eq. wt. (found) 295.44 required for $\mathrm{C}_{17} \mathrm{H}_{14} \mathrm{O}_{5}$ eq. wt. 298.

1-Furyl-3-carbomethoxy-4,4-diphenyl Buta-1,3-diene-2-oic Acid (5e). ${ }^{1} \mathrm{H}$ NMR (300 MHz, DMSO) ( $\left.\delta / \mathrm{ppm}\right): 2.99$ (s, 3H, methoxy protons), 6.276-6.289, 6.38-6.63, 6.55-6.76 (AMX, $3 \mathrm{H}$, furyl), 7.1 (s, 5H, phenyl), 7.5 (s, 5H, phenyl), 7.52 (s, $1 \mathrm{H}$, vinyl). FTIR $\left(\mathrm{KBr}, \mathrm{cm}^{-1}\right.$ ) 634, 712 (mono-substituted $\mathrm{Ph}$ rings), $1172(\mathrm{C}-\mathrm{O}), 1660$ ( $\mathrm{C}=\mathrm{O}$ acid), 1710 ( $\mathrm{C}=\mathrm{O}$ ester), $2510\left(-\mathrm{OCH}_{3}\right)$. UV $\lambda_{\max }(\mathrm{EtOH}) 254 \mathrm{~nm}(\log \varepsilon 4.2)$. eq. wt. (found) 372.00 required for $\mathrm{C}_{23} \mathrm{H}_{18} \mathrm{O}_{5}$ eq. wt. 374.39 .

1,4-Difuryl-3-carbomethoxy Buta-1,3-diene-2-oic Acid (5f). ${ }^{1} \mathrm{H}$ NMR (300 MHz, DMSO) ( $\left.\delta / \mathrm{ppm}\right): 3.72$ (s, 3H, methoxy protons), 6.385-6.409, 6.632-6.663, 7.422-7.447 (AMX pattern repeated, $6 \mathrm{H}$, furyl protons), $7.67(\mathrm{~s}, 1 \mathrm{H}$, vinyl), 7.77 (s, 1H, vinyl). FTIR (KBr, cm ${ }^{-1}$ ) 634, 712 (mono-substituted $\mathrm{Ph}$ rings), $1200(\mathrm{C}-\mathrm{O}), 1625(\mathrm{C}=\mathrm{C}), 1660$ ( $\mathrm{C}=\mathrm{O}$ acid), $1720(\mathrm{C}=\mathrm{O}$ ester $), 2500\left(\mathrm{OCH}_{3}\right) . \mathrm{UV} \lambda_{\max }(\mathrm{EtOH}) 333 \mathrm{~nm}$ (log $\varepsilon 4.6$ ). eq. wt. (found) 290.00 required for $\mathrm{C}_{15} \mathrm{H}_{12} \mathrm{O}_{6}$ eq. wt. 288.24 (see Scheme 3).

Procedure for Preparation of 1,1-Cyclopentylidene-1',2-dicarboxy, 3 (2-furyl)-2-propene (6a). Acid ester 5a (1 g) was dissolved in $30 \mathrm{~mL} 8 \%$ alcoholic $\mathrm{KOH}$ and refluxed for $5 \mathrm{hr}$. It was filtered hot and cooled. Acidification with ice-cool conc. $\mathrm{HCl}$ gave the diacid $\mathbf{6 a}$ as dark brown crystals on recrystallization from benzene pet. ether.

${ }^{1} \mathrm{H}$ NMR (300 MHz, DMSO) ( $\left.\delta / \mathrm{ppm}\right): 1.25-2.17$ [m, $8 \mathrm{H}$, alicyclic $\mathrm{CH}_{2}$ ] 7.20-7.26 [AMX, 3H, furyl], $7.5[\mathrm{~s}, 1 \mathrm{H}$, vinyl]. FTIR. (KBr, cm ${ }^{-1}$ ) $1174.80(\mathrm{C}-\mathrm{O}), 1488.10$ (alicyclic $\left.\mathrm{CH}_{2}\right), 1694.00$ and 1710.00 ( $\mathrm{C}=\mathrm{O}$ unsaturated acid). UV $\lambda_{\max }$ 


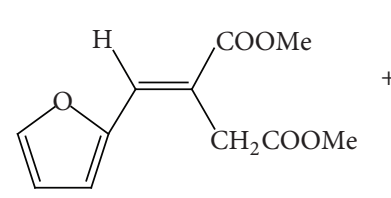

4<smiles>[R]C(C)=O</smiles>

CHEME 3

\begin{tabular}{lccc}
\hline Entry & Ketone/aldehyde & Half-ester & Diacid \\
\hline 1 & Cyclopentanone & $\mathbf{5 a}$ & $\mathbf{6 a}$ \\
2 & Cyclohexanone & $\mathbf{5 b}$ & $\mathbf{6 b}$ \\
3 & Acetone & $\mathbf{5 c}$ & $\mathbf{6 c}$ \\
4 & Benzaldehyde & $\mathbf{5 d}$ & $\mathbf{6 d}$ \\
5 & Benzophenone & $\mathbf{5 e}$ & $\mathbf{6 e}$ \\
6 & Furfural & $\mathbf{5 f}$ & $\mathbf{6 f}$ \\
\hline
\end{tabular}

(EtOH): $357.00 \mathrm{~nm}$ (log $\varepsilon 4.6)$. eq. wt. (found) 130.00 required for $\mathrm{C}_{14} \mathrm{H}_{14} \mathrm{O}_{5}$ eq. wt. 131.13 .

1,1-Cyclopentylidene-1',2-dicarboxy, 3 (2-furyl)-2-propene (6b). ${ }^{1} \mathrm{H}$ NMR $(300 \mathrm{MHz}, \mathrm{DMSO})(\delta / \mathrm{ppm}): 1.55(\mathrm{~s}, 6 \mathrm{H}$, alicyclic $\left.\mathrm{CH}_{2}\right), 2.1\left(\mathrm{~s}, 2 \mathrm{H}\right.$, alicyclic $\left.\mathrm{CH}_{2}\right), 2.81(\mathrm{~s}, 2 \mathrm{H}$, alicyclic $\mathrm{CH}_{2}$ ), 6.383-6.396, 6.62-6.63, 7.43-7.44 (AMX, 3H, furyl),

7.69 (s, $1 \mathrm{H}$, vinyl). FTIR $\left(\mathrm{KBr}, \mathrm{cm}^{-1}\right) 1214(\mathrm{C}-\mathrm{O}), 1600$ ( $\mathrm{C}=\mathrm{C}), 1688$ (C=O acid). UV $\lambda_{\max }(\mathrm{EtOH}) 278 \mathrm{~nm}(\log \varepsilon 4.6)$. eq. wt.(found) 140.64 required for $\mathrm{C}_{15} \mathrm{H}_{16} \mathrm{O}_{5}$ eq. wt. 138.14. 1,1-Cyclopentylidene-1',2-dicarboxy, 3 (2-furyl)-2-propene (6c). ${ }^{1} \mathrm{H}$ NMR $(300 \mathrm{MHz}, \mathrm{DMSO})(\delta / \mathrm{ppm}): 1.75(\mathrm{~s}, 3 \mathrm{H}$, aliphatic $\left.\mathrm{CH}_{2}\right), 2.32\left(\mathrm{~s}, 3 \mathrm{H}\right.$, aliphatic $\left.\mathrm{CH}_{2}\right), 6.448-6.592$, 6.712-6.718, 7.468-7.48 (AMX, 3H, furyl), 7.5 (s, $1 \mathrm{H}$, vinyl). FTIR $\left(\mathrm{KBr}, \mathrm{cm}^{-1}\right) 1218(\mathrm{C}-\mathrm{O}), 1600(\mathrm{C}=\mathrm{C}), 1698(\mathrm{C}=\mathrm{O}$ acid). UV $\lambda_{\max }(\mathrm{EtOH}) 280 \mathrm{~nm}(\log \varepsilon 4.5)$. eq. wt. (found) 121.23 required for $\mathrm{C}_{12} \mathrm{H}_{12} \mathrm{O}_{5}$ eq. wt. 118.11.

1-Furyl-2,3-dicarboxy-4 Phenyl Buta-1,3-diene (6d). ${ }^{1} \mathrm{H}$ NMR (300 MHz, DMSO) ( $\delta / \mathrm{ppm}): 6.376-7.01,7.331-7.429$, 7.35-7.46 (AMX, 3H, furyl), 7.5 (s, 5H, phenyl), $7.72(\mathrm{~s}, 1 \mathrm{H}$, vinyl), 7.89 (s, $1 \mathrm{H}$, vinyl). FTIR $\left(\mathrm{KBr}, \mathrm{cm}^{-1}\right) 1228(\mathrm{C}-\mathrm{O})$, $1628(\mathrm{C}=\mathrm{C}), 1690\left(\mathrm{C}=\mathrm{O}\right.$ acid). UV $\lambda_{\max }(\mathrm{EtOH}) 370 \mathrm{~nm}$ ( $\log \varepsilon 4.6$ ). eq. wt. (found) 143.28; required for $\mathrm{C}_{16} \mathrm{H}_{12} \mathrm{O}_{5}$ eq. wt. 142.31 .

1-Furyl-2,3-dicarboxy-4,4 '-diphenyl Buta-1,3-diene (6e). ${ }^{1} \mathrm{H}$ NMR (300 MHz, DMSO) ( $\delta / \mathrm{ppm}): 6.71-6.73,6.80-6.85$, 6.87-6.89 (AMX, 3H, furyl), 7.65 (s, 5H, phenyl), 7.75 (s, $5 \mathrm{H}$, phenyl), 7.81 (s, $1 \mathrm{H}$, vinyl). FTIR $\left(\mathrm{KBr}, \mathrm{cm}^{-1}\right) 613,620$ (mono-substituted $\mathrm{Ph}$ rings), $1170(\mathrm{C}-\mathrm{O}), 1648(\mathrm{C}=\mathrm{O}$ acid), 1700 (C=O acid). $\mathrm{UV} \lambda_{\max }(\mathrm{EtOH}) 270 \mathrm{~nm}(\log \varepsilon 4.6)$. eq. wt. (found) 179.95 required for $\mathrm{C}_{22} \mathrm{H}_{16} \mathrm{O}_{5}$ eq. wt. 180.19.

1,4-Difuryl-2,3-dicarboxy Buta-1,3-diene (6f). ${ }^{1} \mathrm{H}$ NMR

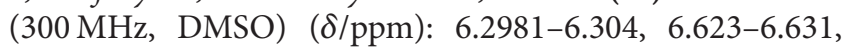
7.434-7.438 (AMX pattern repeated, $6 \mathrm{H}$, furyl protons), 7.67 (s, $1 \mathrm{H}$, vinyl), 7.77 (s, $1 \mathrm{H}$, vinyl). FTIR $\left(\mathrm{KBr}, \mathrm{cm}^{-1}\right) 1250$
(C-O), $1635(\mathrm{C}=\mathrm{C}), 1690$ (C=O acid). UV $\lambda_{\max }(\mathrm{EtOH})$ $332 \mathrm{~nm}$ ( $\log \varepsilon 4.76)$. eq. wt. (found) 138.40 required for $\mathrm{C}_{14} \mathrm{H}_{10} \mathrm{O}_{6}$ eq. wt. 137.11 .

\section{Results and Discussion}

In the previous research [17], it was found that potassium tertiary butoxide can be smoothly used as a catalyst in Stobbe condensation under solvent-free conditions. This discovery stimulated us to explore whether it could be developed into a green [18] procedure for Stobbe condensation.

Stobbe condensation generally involves the use of metal alkoxide as a catalyst in refluxing alcohol, and particularly, butanol. On the other hand, in the present paper, the use of butanol is discarded and instead, dry solid potassium tertiary butoxide is taken for the reaction. The advantages are inexpensive and easily available materials, have short reaction time, excellent yields (the yields of the products obtained by solvent-free method were compared with the yields of the products obtained by classical method which was done simultaneously for a comparative study), and environmentfriendly reaction conditions.

A well ground mixture of furfural $\mathbf{1}$ and dimethyl succinate 2 in 1:1 molar ratio with catalytic amount of potassium tertiary butoxide without any solvent was exposed to atmosphere at room temperature in a dry agate mortar. After neutralization with dil. $\mathrm{HCl}$, crude 3-carbomethoxy,4furyl, 3-butenoic acid, 3 which could be easily crystallized from benzene-petroleum ether. The structure of the acid ester 3, has been analyzed by UV, IR, and NMR spectra. It is confirmed that, from both the routes, namely, classical Stobbe condensation [15] and the solvent-free reaction, the same acid ester $\mathbf{3}$ is obtained.

The acid ester product upon methylation with diazomethane [16] afforded diester, namely, methyl 3-carbomethoxy,4-furyl,3-butenoate, 4 in 95\% yield.

The diester $\mathbf{4}$ is a starting material for the synthesis of various butadienes via Stobbe condensation with different aldehydes (furfural, benzaldehyde) and ketones (acetone, benzophenone, cyclopentanone, and cyclohexanone) using the base, that is, dry-solid potassium tert. butoxide in an oven-dried mortar at room temperature (see Figure 1 and Table 1).

The results indicated that, all the reactions were performed under solvent-free conditions in good yields of 70-90\% (please see Table 2). The structures of these compounds were analyzed by NMR spectroscopy [19]. All the 


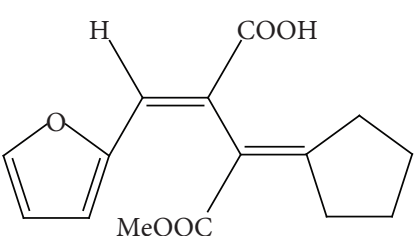

$5 a$<smiles>COC(=O)/C(=C/c1ccco1)C(=O)O</smiles>

$5 d$<smiles>O=C(O)C(=C1CCCC1)/C(=C\c1ccco1)C(=O)O</smiles>

$6 a$<smiles>O=C(O)C(=Cc1ccccc1)/C(=C\c1ccco1)C(=O)O</smiles>

6d

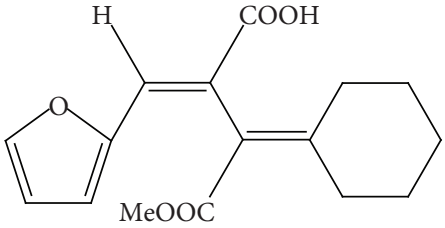

$5 b$<smiles>COC(=O)C(C(=O)c1ccccc1)=C(C(=O)O)c1ccco1</smiles>

$5 e$

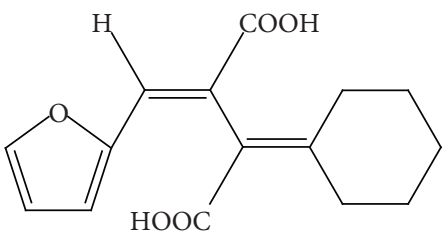

$6 b$<smiles>O=C(O)C(=C(c1ccccc1)c1ccccc1)/C(=C\c1ccco1)C(=O)O</smiles>

$6 e$<smiles>COC(=O)C(C(=O)OCc1ccco1)=C(C)C</smiles>

$5 c$<smiles>COC(=O)/C(=C\c1ccco1)C(=O)O</smiles>

$5 f$<smiles>CC(C)=C(C(=O)O)C(=Cc1ccco1)C(=O)O</smiles>

$6 c$<smiles>O=C(O)/C=C(/C=C\c1ccco1)C(=O)O</smiles>

$6 f$

FIGURE 1: Stobbe products $\mathbf{5 a - f}$ and diacids $\mathbf{6 a}-\mathbf{f}$.

TABLE 2: Yield and melting points of Stobbe products $\mathbf{3}, \mathbf{5 a}-\mathbf{f}$.

\begin{tabular}{lccc}
\hline Compound & \multicolumn{2}{c}{ Yield \% } & $\mathrm{mp}\left({ }^{\circ} \mathrm{C}\right)$ \\
\hline $\mathbf{3}$ & Classical & Green & 111 \\
$\mathbf{5 a}$ & 65 & 83 & 162 \\
$\mathbf{5 b}$ & 63 & 78 & 120 \\
$\mathbf{5 c}$ & 75 & 82 & 102 \\
$\mathbf{5 d}$ & 65 & 70 & 194 \\
$\mathbf{5 e}$ & 62 & 74 & 128 \\
$\mathbf{5 f}$ & 60 & 71 & 160 \\
\hline
\end{tabular}

butadienes, being derived from furfural, show a common AMX pattern in their high resolution NMR spectra, which can be seen for three furyl hydrogens nearly at $6.3,6.6$, and $7.6 \delta$. Aromatic protons are depicted well in the aromatic zone of $7.2-7.5 \delta$ for the compound $5 \mathbf{d}$ and $\mathbf{6 d}$. Similarly, the aliphatic and alicyclic protons are exhibited in their
TABLE 3: Yield and melting points of dicarboxylic acids $\mathbf{6 a - f .}$

\begin{tabular}{lcc}
\hline Compound & Yield \% & $\mathrm{mp}\left({ }^{\circ} \mathrm{C}\right)$ \\
\hline 6a & 85 & 168 \\
6b & 85 & 177 \\
6c & 86 & 180 \\
6d & 90 & 202 \\
6e & 88 & 132 \\
6f & 89 & 230 \\
\hline
\end{tabular}

characteristic positions. Further, FTIR spectra [20] support the structures of the compounds. The typical acid carbonyl is found in the range $1670-1690 \mathrm{~cm}^{-1}$, and the ester $\mathrm{C}=\mathrm{O}$ appears at near $1715 \mathrm{~cm}^{-1}$.

It is interesting to note that the saponification [15] reactions of the acid esters $\mathbf{5} \mathbf{a}-\mathbf{5} \mathbf{f}$ afforded the diacids $\mathbf{6} \mathbf{a}-\mathbf{6 f}$ in good yields (please see Table 3). 
The presence of different substituents does not really affect the product yield. However, during cyclization of these diacids, difficulty is faced with the bulkier phenyl or naphthyl substituents, which would be discussed elsewhere.

\section{Conclusion}

It was concluded that, the solvent-free condensations of substituted ketones and/or aldehyde with dimethyl succinate at room temperature occurred smoothly to give substituted acid esters. As compared to the classical condensation method done by previous workers [13], wherein was required, plenty of solvents and chemicals to proceed, the green method needed much less amount of dry solid reagents; which indicates that the method is efficient from the economical point of view. No heat energy is required for the formation of acid esters, thus, proving the reaction to be feasible at ecofriendly reaction conditions. Further, this method improved the yields and shortened the reaction time.

\section{Acknowledgments}

One of the authors is thankful to AASCON (Alumni Association of Science colleges of Nagpur) for financial assistances and to SAIF, Punjab University, for providing spectral data.

\section{References}

[1] K. Amimoto and T. Kawato, "Photochromism of organic compounds in the crystal state," Journal of Photochemistry and Photobiology C, vol. 6, no. 4, pp. 207-226, 2005.

[2] S. Nithynandan, C. Saravanan, S. Senthil, and P. Kannan, "Microwave-assisted synthesis of photochromic fulgides," Journal of Chemical Sciences, vol. 122, pp. 183-188, 2010.

[3] M. Fan, L. Yu, and W. Zhao, "Fulgide family compounds: synthesis, photochromism and applications," in Main Photochromic Families, J. C. Crano and R. J. Guglielmetti, Eds., chapter 4, p. 141.

[4] G. H. Daub and W. S. Johnson, "The Stobbe condensation with sodium hydride," Journal of the American Chemical Society, vol. 72, no. 1, pp. 501-504, 1950.

[5] D. L. Turner, "Preparation of a cyclopentenone by the Stobbe condensation," Journal of the American Chemical Society, vol. 75, no. 5, pp. 1257-1258, 1953.

[6] A. M. El-Abbady and H. H. Mousa, "Studies on stobbe condensation: reactions of aldehydes and ketones with dimethyl methylsuccinate," Canadian Journal of Chemistry, vol. 43, no. 4, pp. 928-934, 1965.

[7] R. N. Hurd and D. H. Shah, "Stobbe condensations of dimethyl 3,5-bis(benzyloxy)homophthalate," The Journal of Organic Chemistry, vol. 38, no. 3, pp. 607-609, 1973.

[8] J. Lin and N. R. Brooks, "Stereoselective stobbe condensation of ethyl methyl diphenylmethylenesuccinate with aromatic aldehydes," Organic Letters, vol. 4, no. 20, pp. 3521-3524, 2002.

[9] W. Tang, D. Liu, and X. Zhang, "Asymmetric hydrogenation of itaconic acid and enol acetate derivatives with the Rh-tangPhos catalyst," Organic Letters, vol. 5, no. 2, pp. 205-207, 2003.

[10] X. Ya-Mu, Y. Jia, and Q. Wang, "Total synthesis of ( \pm )divanillyltetrahydrofuran ferulate," Journal of Chemical Sciences, vol. 122, no. 3, pp. 433-436, 2010.
[11] J. Harada, R. Nakajima, and K. Ogawa, "X-ray diffraction analysis of photochromic reaction of fulgides: crystalline state reaction induced by two-photon excitation," Journal of the American Chemical Society, vol. 130, no. 22, pp. 7085-7091, 2008.

[12] Q. Sun, L. Shi, Z. Ge, R. Li, and T. Chang, "An efficient and green procedure for the knoevenagel condensation catalyzed by urea," Chinese Journal of Chemistry, vol. 23, no. 6, pp. 745-748, 2005.

[13] S. Banerjee, R. A. Tayade, and B. Sharma, Indian Journal of Chemistry, Section B, vol. 48, p. 882, 2009.

[14] B. K. Sharma, Spectroscopy, Goel Publishing House, New Delhi, India, 13th edition, 1999.

[15] G. Bagavant and S. Banerjee, Current Science, vol. 44, p. 846, 1975.

[16] G. D. Muir, Hazards in the Chemical Laboratory, Royal Institute of Chemistry, London, UK, 1971.

[17] K. Tanaka, T. Sugino, and F. Toda, "Selective Stobbe condensation under solvent-free conditions," Green Chemistry, vol. 2, no. 6, pp. 303-304, 2000.

[18] R. Sanghi and M. M. Srivastava, Green Chemistry, Narosa Publishing House, New Delhi, India, 2003.

[19] J. K. M. Sanders and B. K. Hunter, Modern NMR Spectroscopy, Oxford University Press, Oxford, UK, 2nd edition, 1993.

[20] L. J. Bellamy, The Infrared Spectra of Complex Molecules, Chapman and Hall, London, UK, 1980. 

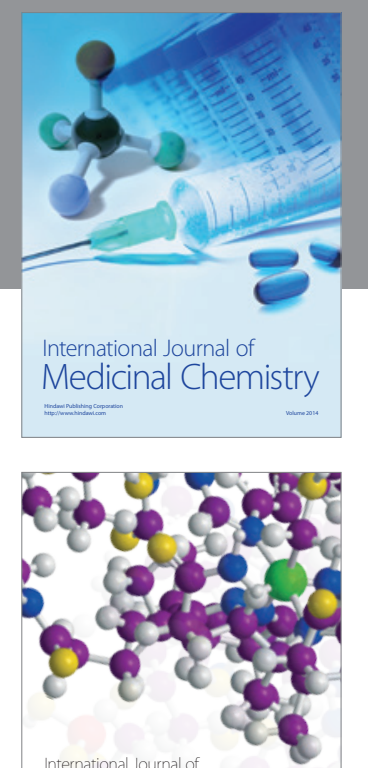

\section{Carbohydrate} Chemistry

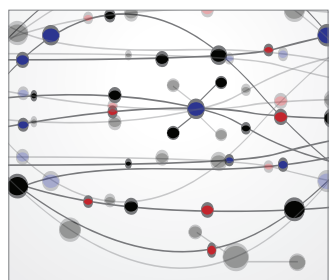

The Scientific World Journal
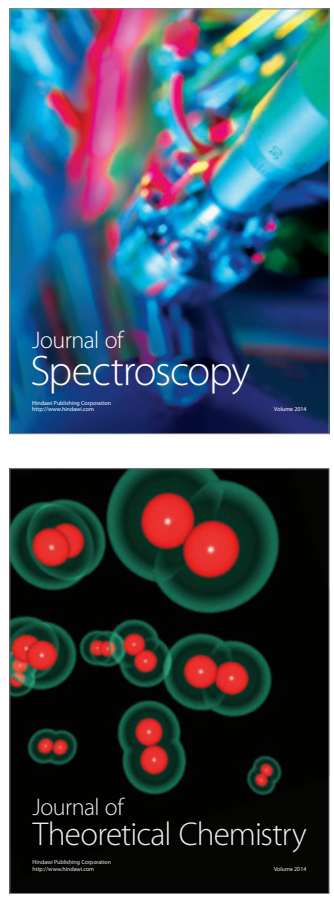
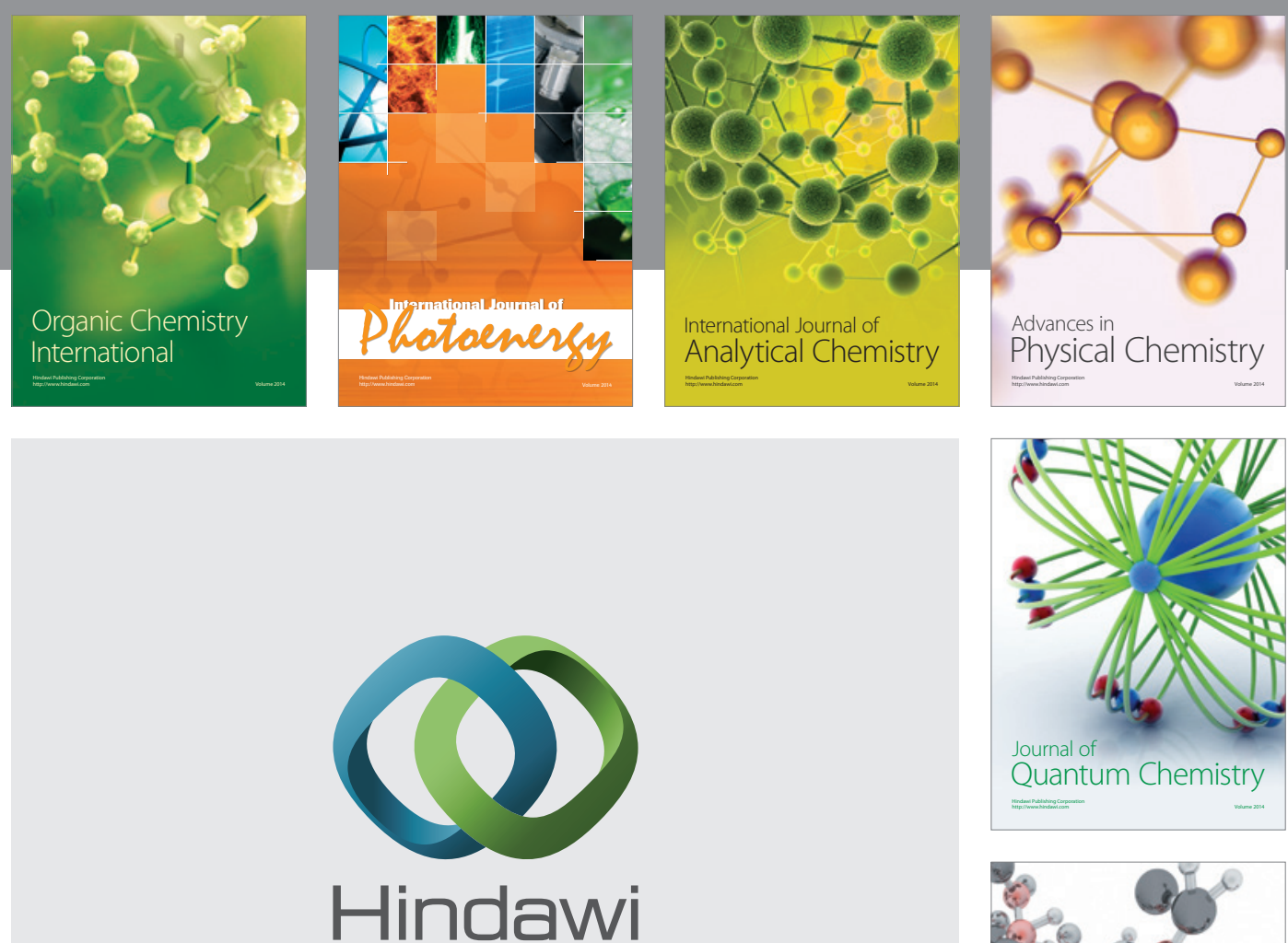

Submit your manuscripts at

http://www.hindawi.com

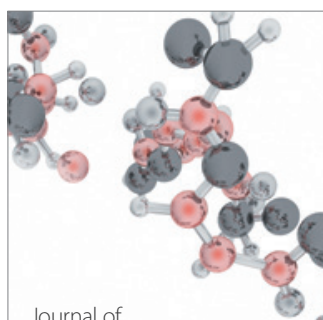

Analytical Methods

in Chemistry

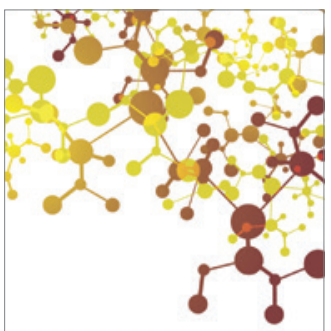

Journal of

Applied Chemistry

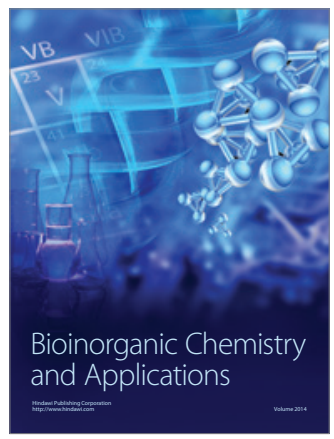

Inorganic Chemistry
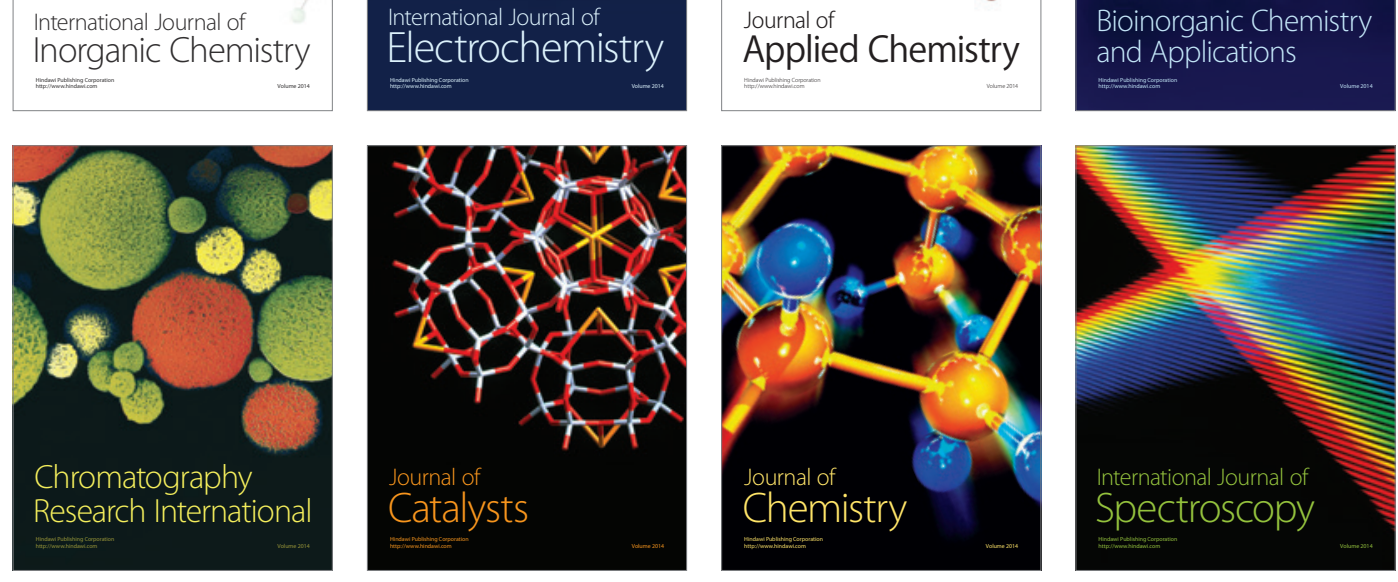